\title{
Steady-state groundwater arsenic concentrations in reducing aquifers
}

\author{
B.C. Bostick ${ }^{1}$, A.A. Nghiem ${ }^{1}$, A. van Geen ${ }^{1}$, J. Sun ${ }^{2}$, B.J. Mailloux ${ }^{3}$, P.H. Viet ${ }^{4}$ \& P.T.K. Trang ${ }^{4}$ \\ ${ }^{1}$ Barnard College and Lamont-Doherty Earth Observatory, Columbia University, New York, USA \\ ${ }^{2}$ University of Western Australia \& CSIRO Land and Water, Perth, WA, Australia \\ ${ }^{3}$ Department of Environmental Sciences, Barnard College, New York, NY, USA \\ ${ }^{4}$ CETASD, Vietnam National University, Hanoi, Vietnam
}

\begin{abstract}
Arsenic is a common soil and groundwater contaminant in much of the world. Groundwater arsenic is commonly derived from the reductive dissolution of arsenic-bearing iron oxides. Despite considerable efforts, it is still difficult to predict the aqueous concentration of arsenic in the transitional redox environments where arsenic release occurs, or in the reduced sediments through which it is transported. Equilibrium-based partitioning models often no more accurate that simple adsorption isotherms or partition coefficients in these environments. Here, we develop and evaluate a novel kinetics-based approach that incorporates knowledge of the solid-phase, to predict arsenic concentrations. This model defines the steady-state aqueous concentration of arsenic as a function of iron oxide dissolution rate and readsorption of arsenite and arsenate. This model uses measured iron and arsenic redox status to successfully describe As concentrations in redox profiles in heterogeneous Bangladeshi and Vietnamese aquifers. These data imply that the speciation of arsenic, which affects readsorption rates, are the dominant variable controlling As retention, and that iron mineralogy plays an indirect role by affecting the rate of biological reduction.
\end{abstract}

\section{INTRODUCTION}

Groundwater arsenic (As) contamination is a global public health problem and also a concern at hundreds of U.S. Superfund sites. A considerable body of research has established that arsenic enters groundwater most commonly through the biological reduction of As-bearing iron oxides. Despite this realization, we are still not able to adequately predict arsenic concentrations at specific sites, or determine how they may be affected as the system evolves. Most predictions are based equilibrium retention by the sediments and predict changes in As concentrations resulting in a change in sediment mineralogy and/or redox status and the change in the quantity of substrate and/or As in the solid-phase. These approaches are broadly consistent with regional trends in that older sediments tend to be oxidized and contain less As due to flushing, but they break down at smaller scales. In this research, we propose that kinetics is the dominant factor that affects As partitioning, and develop a quantitative model to test this hypothesis that is capable of describing As concentrations at specific depths within several depth profiles of dissolved arsenic levels in Vietnam.

\subsection{Modelling}

This simple model is based on the hypothesis that dissolved As is a chemical intermediate between the reductive dissolution that puts it into solution, and adsorption or precipitation processes that remove it from solutions. It assumes that the dissolved As concentrations are at steady-state because retention processes are sufficient that most of the As remains in the solid phase. This model assumes As only resides on $\mathrm{Fe}(\mathrm{III})$ minerals, and that the reduction of those minerals releases them proportionally to concentration. The rate of Fe reduction in the sediments can vary due to many factors but under in situ conditions varies strongly with mineralogy (Postma et al., 2010). The rate of readsorption of arsenic depend on the availability (concentration) of iron oxide substrates, and the concentration and oxidation state of As. Arsenate and arsenite are considered independently - the rate of their release is determined by their abundance in the solid-phase. Because adsorption rates for $\mathrm{As}(\mathrm{V})$ on $\mathrm{Fe}(\mathrm{III})$ oxides are considerably more rapid than As(III) (Kanel et al., 2006), As oxidation state plays a significant, albeit indirect role in regulating As levels.

\subsection{Fe and As speciation}

This model requires knowledge about the solidphase speciation of both $\mathrm{Fe}$ and As. The concentration of solid-phase $\mathrm{Fe}(\mathrm{II})$ and $\mathrm{Fe}(\mathrm{III})$ oxides is determined using synchrotron-based X-ray absorption spectroscopy (XAS) using established techniques ${ }^{5}$. We convert the fractional speciation determined by XAS to solid phase concentrations of $\mathrm{Fe}$ (III) and As(III) 
or $\mathrm{As}(\mathrm{V})$ using X-ray fluorescence (XRF) data collected using a hand-held XRF. We have determined As and Fe speciation every $2 \mathrm{~m}$ for several sites where groundwater concentrations also vary with depth. This fine-scale sampling allows us to explain sharp gradients in groundwater arsenic that occur with depth, and to determine the relative roles of $\mathrm{Fe}(\mathrm{III})$ and $\mathrm{As}(\mathrm{V})$ reduction on regulating As levels.

\section{RESULTS AND DISCUSSION}

This research is unique in that it allowed us study the redox state in layered aquifers where both redox state and As concentrations varied considerably with depth, and where there were coupled changes in dissolved As levels. In most environments, $\mathrm{As}(\mathrm{V})$ and $\mathrm{Fe}(\mathrm{III})$ concentrations are high in the surface, and conditions become more reducing with depth. At most of our, $\mathrm{Fe}$ (III) concentrations decreased gradually with depth, while As reduction was a sharper transition that occurred below the zone where $\mathrm{Fe}(\mathrm{III})$ reduction became apparent. Dissolved As concentrations generally were low at the surface where systems were more oxidized, and there was a sharp gradient between low and high dissolved As concentrations. In more complex layered aquifers systems containing oxidized Pleistocene sediments and reduced Pleistocene sediments, the model was also effective in that dissolved As concentrations oscillated with sediment properties.

The model was able to accurately predict dissolved As levels within a factor of 2 at all depths using measured Fe(III) oxide, As(III) and As(V) solid-phase concentrations, and without any information about groundwater composition. Dissolved As levels mirrored As speciation. Based on these data, we were able to model dissolved As concentrations over a wide

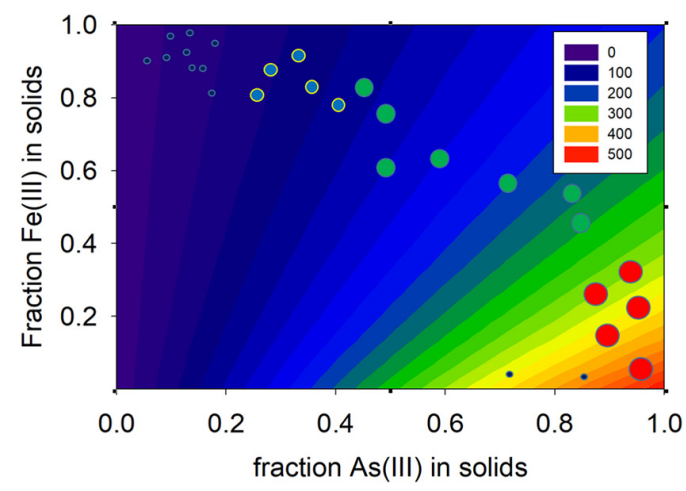

Figure 1. Modeled contour plot of dissolved As concentrations (legend shows color scale) as a function of solid-phase $\mathrm{Fe}$ and As oxidation state, with selected data plotted on the figure with symbols sizes and colors proportional to concentration. range of As and $\mathrm{Fe}$ oxidation states given a small number of assumptions about the concentration of $\mathrm{Fe}$ and As in the sediments, and the reactivity of the Fe(III) oxides in the system (Fig. 1). Most As concentrations from sediment profiles was effectively described, with the possible exception of some highly reduced sediments.

\section{CONCLUSIONS}

The model successfully predicts dissolved As concentrations without refinement of kinetic parameters. This adherence suggests that the assumption that dissolved As can be thought of effectively as a reactive intermediate in the environment.

There are several important applications of this model. First, As concentrations appear to vary with depth because of differences in the rates of retention of $\mathrm{As}(\mathrm{III})$ and $\mathrm{As}(\mathrm{V})$ rather than differences in their equilibrium adsorption isotherms on aquifer sands. Second, because redox gradients of Fe and As vary from each other spatially, it allows us to identify the relative roles of As and $\mathrm{Fe}$ reduction on generating high-As groundwater. Fe gradients are more gradual, and even in most reduced sediments, a considerable fraction of Fe(III) phases remain. Dissolved As concentrations will be highest when reduction rates are fastest, meaning that As concentrations will be elevated most in the presence of reactive Fe oxides such as ferrihydrite. Third, As oxidation state appears to play a much more important role in regulating As levels than does $\mathrm{Fe}$ speciation. This model does not consider the rates of As reduction, however, parallel recent research suggests that biologically mediated $\mathrm{As}(\mathrm{V})$ reduction is prevalent where As(III) is found. These results suggest that As levels will be highest where there is a combination of high levels of As(III) retained on reactive $\mathrm{Fe}(\mathrm{III})$ oxides, and that remediation efforts should concentrate on modulating the rates of retention to be effective.

\section{ACKNOWLEDGEMENTS}

U.S. National Institute of Environmental Health Sciences (grant ES010349 and ES009089) and U.S. National Science Foundation (grants 1521356 and 0911557).

\section{REFERENCES}

Kanel, S.R., Greneche, J.M. \& Choi, H. 2006. Arsenic(V) removal from groundwater using nano scale zero-valent iron as a colloidal reactive barrier material, Environ. Sci. Technol. 40: 2045-2050.

Postma, D., Jessen, S., Hue, N.T.M., Mai, T.D., Koch, C.B., Viet, P.H., Nhan P.Q. \& Larsena, F. 2010. Mobilization of arsenic and iron from red river floodplain sediments, vietnam. Geochim. Cosmochim. Acta 74: 3367-3381. 